\title{
Towards a sustainable, negotiated mode of strategic regional planning: a political economy perspective
}

\author{
Ian Gordon \\ (Department of Geography and Environment, London School of Economics) \\ Corresponding author: I.R.Gordon@lse.ac.uk \\ and \\ Tony Champion \\ (Centre for Urban and Regional Development Studies, Newcastle University) \\ Tony.Champion@newcastle.ac.uk
}

Final submitted draft April 2020

\begin{abstract}
:
The need to give strategic direction to complex regional systems has never been greater, but reinstating a classic strategic plan model which failed to secure consistently positive impacts, or even sustain its own practice is a mistaken route. With a mix of conceptual analysis, critical review of past experience, and an examination of population dynamics across England's Wider South East and its fringes this paper argues for a decentred form of strategic governance based on the development of a capacity for negotiated collaboration and realistic engagement with powerful market and institutional processes on a sustained basis.
\end{abstract}

\section{Introduction: A Rationale for Decentring Strategic Regional Planning}

Planning is a contested terrain: not only in ideological terms (market liberalism versus social redistribution), materially (in the allocation of windfall gains), and culturally (as it cuts across diverse communities); but also crucially in relation to the authority of 'planners' vis-à-vis other specialist/professional groups. Coming late to the professional 'ball' - within the last century, after engineers, architects and public health practitioners - and without ongoing service delivery functions to sustain them, except in low level development control activities, planners have generally experienced a structural weakness in securing their potential position as the integrators of societal activity at a city/regional scale. This insecurity has been reflected both in rotation between a set of legitimating heuristics (e.g. the planner as technician, bureaucrat, community advocate or normatively validated professional ${ }^{1}$ ) and fluctuating levels of political acceptance. 
There have ensued (in the global 'north' at least) recurring phases of active debate about both 'planning theory' and appropriate forms of professional education (see e.g. Fainstein and De Fillippis, 2015; Friedmann, 2012). Though such debates continue, with shifting emphases, the strongest pair of cards in marking planners' particular professional strength has long involved claims to: possession of a particularly comprehensive vision; plus particular attention to spatial relations and integration. Strategic spatial plans at regional scale (or beyond) assume an iconic status then, in embodying the highest forms of the planner's craft. As well as (hopefully), offering a more secure context (in social, economic and environmental terms) within which operational/regulatory planning can be undertaken across the gamut of public and private activity.

For practitioners, strategic planning's broader context seems to offer a welcome freedom from the inherited constraints and rivalries that beset everyday, localised planning and development control. It looks less of a contested terrain. The reality is, however, that any effective strategic planning (even in the most authoritarian settings) depends on somehow securing credible commitments from other agents with real power, on key lines of action they will take (or refrain from), given the vision they are being offered. Despite vigorous debates about the form and logic of strategic planning, this crucial general point tends to get lost - though John Friedman's (1993) argument for a new 'non-Euclidian planning model' notably emphasised the need for a more entrepreneurial perspective, with planners acting primarily as 'resource mobilisers who seek to concert public and private energies around innovative solutions to stubborn problems in the public domain' (p. 485).

Strategic planning can be characterised normatively as embodying a longer run, spatially broader and more fundamentally grounded perspective on choice issues. But it is also a matter of 'situated practice' (Albrechts et al., 2017), involving work as well as ideas, and needing to be pursued differently as the circumstances of a time and place affect how those functional requirements might best be met. And when it 'fails', the manner in which it does so will also reflect such situational influences - though there are likely to be some common, underlying factors.

Making use of experience to understand what is generally applicable, offering some kind of useful lesson of wider relevance, and distinguishing that from what is specific to particular types of situation, cannot, however, be simply a matter of induction from reported cases. It also depends on thinking more intensively about what has happened in a few situations (maybe one at a time), and the sorts of potentially generic factors underlying these - at least as hypotheses for wider testing. That is closer to the approach of this paper, which starts from a casual generalisation about the problematic record of strategic regional planning, for which it seeks to offer some analytic explanation and suggest some possible general lessons for the future, using a single, familiar regional case for illustration (rather than corroboration).

Both the argument and the method reflect a critical approach - to the standard model of strategic spatial planning, its basis in planning theory, and the disciplinary limits of planning research - which is rather close to that of Salet (2017). From a sociological perspective (and in the context of a collection of situated studies of strategic planning initiatives) he argued that work in this field has suffered from a planner-centric subjectivism, which evolved in the 
era of welfare state construction (and/or, we might say, industrial Fordism) but is completely out of place in the more uncertain times of recent decades. Maybe it was ever thus, but has just become more evidently so, as (and where) the political climate has become less supportive of strategic planning - and experience exposed its limitations. As Salet frames it, this subjectivism is largely an intellectual problem - of 'thought and action perspectives (which) tend to consider the planning subject (i.e. the planner) as the centre of all action'. But it is one that is compounded by a voluntaristic tendency for planners to frame projects in a manner driven by their own normative perspective, rather than seriously considering alternatives reflective of wider social forces (pp 375-8). Both of these negative tendencies might be seen as reflecting claims to professional legitimacy based on planners' particular capacity to maintain a comprehensive viewpoint.

The other side of this planner-centrism, in research as well as in strategic planning practice has been a particular reluctance to engage with the power and reactive capacity of political or economic actors and institutions. At the level of planning theory, Friedmann (2012) suggested that:

'the biggest problem we face... is our ambivalence about power': 'the rational planning paradigm studiously avoided talking about any form of power other than the power of the mind'; the knowledge/action paradigm was blocked from saying how new visions might be implemented 'because implementation requires an acknowledgement of power as a central issue'; and the communicative action paradigm had a 'Panglosssian view of the power of dialogue to bridge the gap between those who command substantial power and those who do not' (p. 137).

At the level of strategic planning practice, powerful economic and political processes tend to be treated either in some anodyne form as contextual elements or as purely exogenous factors to be handled through forecasts of their effects.

What is sadly missing is recognition of either kind of process as: a dynamic element responding opportunistically to plan proposals and forecasts; or involving agents whose potentially active support or resistance could be crucial, both at plan-making and implementation stages. For example, in the situated practice cases of Albrecht et al's (2017) handbook, direct references to market or political behaviour (as distinct from economic trends and policy decisions) rarely appear, with only a Chinese case (Xu and Yeh, 2017) addressing spatial politics as a significant factor. And Albrecht's own (2013) reframing of strategic planning in terms of a potential co-production model, while involving a loosening up of planners' direct control, does so on a basis even more driven by their idealistic norms, with no specific attention to how planning activity actually interacts with markets or politics, beyond generally baleful effects attributed to 'neo-liberalism'.

We agree with Albrecht (and other planning theorists) that a reframing of the conventional strategic planning model is required. And also with more practice-oriented colleagues about the urgent need, in England at least, for a revived and strengthened strategic element in development planning (CFN, 2017; Bowie, 2018). Our view, however, is that a much more radical rethinking is required - in relation to theory, practice and research - of how that strategic element can be effectively (and positively) pursued, on a basis which is decentred, spatially, professionally and intellectually, from the classic focus on production of strategic regional plans. 
We start from three basic propositions:

- that the form, scale and complexity of currently pressing issues and uncertainties facing communities around the world requires a stronger strategic - longer term, spatially broader and more fundamental - dimension to city/regional planning;

- that past efforts to pursue plan-based strategic approaches have commonly been bedevilled by a lack of durable support for them, falsified assumptions about the direction and scale of key changes, unconsidered barriers to desired policy impacts and important unintended consequences; and

- that a common cause of such failure is inattention to strong economic and political forces outwith the direct control (and professional orientation) of strategic planners - remedying which is key to a more genuinely strategic planning process.

The following sections of the paper pursue this line of argument in three steps, moving from general processes via illustrative examples from the UK - focused particularly on the strategic challenges to governance presented by strong and contentious currents of population mobility across a much extended capital city region (the Wider South East) - to implications for a more realistic and durable model of strategic planning, there and elsewhere. Two running themes are the need to think of the strategic planning process as itself a long term, continuing activity; and to recognise practical attention to institutionbuilding on a sustained basis as an integral part of that process. Our approach is identified as a political economy one, not because it follows one of the classic (macro-oriented) schools, but because it asserts the need to attend closely to interacting political and economic processes, if strategic regional planning is to be credibly worthwhile.

\section{The Argument: Strategic Regional Plans versus Effective Strategic Planning}

In this section we develop the case for a decentred approach to strategic regional planning as a process-based and sustained enterprise, rather than one embodied in the development, implementation and occasional revision of an authoritative strategic plan. We start by outlining the set of ideas on which it draws from inside and outside the planning canon, before setting out a set of first principles, then summarising ways in which significant British strategic planning initiatives of the past 75 years have fallen short of reasonable expectation for them, and finally suggesting some generic lessons that might be drawn.

\section{Sources in the literature}

The conceptual underpinning of this paper draws on a mix of ideas from several distinct sources: classical and post-modern writing about planning theory; empirical research on metropolitan governance; and a political economy perspective on territorial competition. The sources (and provocations) are doubtless very many, drawn from past engagement with several mainstream literatures. But the originality of our argument generally comes from what we emphasise and combine rather than from specific sources, so the referencing is limited and indicative in character. 
As a point of entry, we take two foundational distinctions from classic planning theory (as represented in Faludi 1973). One distinction is that between a comprehensive rational approach to planning, with complex systems being managed through hierarchies of plans (from strategic to operational), and disjointed incrementalism, a piecemeal politically-driven alternative, dealing reactively to 'signals' from interacting interest representatives (LIndblom's (1965) 'partisan mutual adjustment') about what requires attention. The other distinction is between a static view of planning as engaged periodically in the production of blueprints for future development and a more dynamic one involving a set of processes jointly shaping the path of change on a continuing basis. Our view leans toward the disjointed and process sides of these dualisms, but with an understanding that increments don't have to be modest when a pressing issue is seen to require more, and that key processes for management of change often lie outwith the 'planning system'.

From (a rich variety of) post-modern re-theorisations of planning we take another pair of ideas. One is that of communicative rationality, involving processes of critical and creative interaction between diverse parties with a realistic aim of securing enhanced understanding and progress toward better outcomes, rather than an agreed vision (Healey, 1992). The other is that of imagined communities or spatial imaginaries (Davoudi, 2018), involving shared understandings of identity and difference that are significantly political both in their effects in structuring arguments about change and in the experiences that shape them. Our particular take on both of these ideas is more strategic than most of their exponents advocate, involving a greater emphasis on coalition building processes than on normative democracy, and focusing on the significance of imagining not only friendly neighbours to band together with but also spatial enemies as constraints to be overcome.

From recent work on metropolitan governance we take one further set of related ideas involving: the importance of voluntary collaboration between local municipalities; the difficulties of achieving this in practice; and the key role of a notion of civic capital, involving shared understandings and thick networks. More specifically, it emphasises the importance of leaders - people or organisations with capacities both as bridge-builders and catalysts for collective action through engagement in projects (Nelles, 2012; Gordon, 2006).

Finally, we draw another pair of ideas from writings about territorial competition (in relation to the advancement of place-based sets of economic interests). One is that representations of collective interests (of the kind deployed in strategic plans) emerge from a political interplay between actors with different types and degrees of stake in placespecific outcomes and with different levels of resources to deploy. The other is that the active engagement of actors in pursuit of their collective interests cannot be taken for granted, but depends on a judgement about its likely efficacy for them, where existence of a few players with very strong stakes and the ability to mobilise collectively may often be crucial for what happens (Cheshire and Gordon, 1996).

Rather little in the elements which we have picked out here explicitly addresses the possibility of worthwhile strategic planning. But together - and with an understanding of the centrality of self-oriented decision-making by very large numbers of independent agents for how city-regions evolve - they suggest to us where the scope for effective strategic action can be found, as well as why the classic model is unlikely to have it. 


\section{Some First Principles}

Our characterisation of strategic planning suggests that it should be a more thoughtful activity than everyday planning, where robust standard operating procedures (SOPs) and assumptions are generally adequate. But, as each of these literatures suggest, it cannot be a purely intellectual activity, if it is to command any attention, to make a (positive) practical difference and be sustained, in a real world where SOPs, short-term politics and/or privately directed strategies are the norm.

To focus attention on what else is required, we propose half a dozen key principles - starting from the functions expected of a strategic approach, the circumstances in which these particularly matter, relations with other types of strategically significant process, through to the crucial issue of securing relevant action:

I. The distinctive function of the strategic dimension in planning is to secure a purposive and positive sort of coherence in the operation of a complex system with inherent sources of uncertainty. In a spatial context such complexity and uncertainty is particularly associated with larger urban regions, characterised by high levels of diversity in activities, peoples and place-types, with multiplex networks of interaction over extended territories.

II. The challenges of securing coherence in such situations are beyond the strategic capacities of even the smartest single organisation, profession (or indeed state), acting on their own. This applies even, or particularly, to establishing the directions in which it would be good for it to be steered - what might count as 'good steering' in a statement of planning objectives.

III. The actual steering (i.e. governance) of cities/regions needs to be recognised as an amalgam of three interacting elements, including markets and informal institutions as well as planning. As well as authoritative policy-making and enforcement from official nodes (planning); these involve structured interaction between very large numbers of, more or less, self-serving agents (markets)); and sets of beliefs/understandings, shared identities, and habits of co-operation/ antagonism (informal institutions). As a first approximation, these may be seen as independent and of comparable importance, but patterns of accommodation between them matter and may be shifted (Gordon, 2006, 2016).

IV. It is crucial for planners to recognise the real power of the other two elements of governance, particularly in terms of how their dynamic reactions to 'plans' can alter forecast outcomes. The temptation not to do so seems especially great for strategic planners who aspire to transcend more mundane, local and transient features. But planning that is blind to the importance of two thirds of the governance system, how they respond to planned initiatives, and how these might be trained in more positive directions, cannot itself be expected to have positive strategic impacts.

V. More specifically, it needs to be better understood that ignored market responses can lead to quite perverse effects from key policies. This is especially likely when investment markets actually embody a longer term view than planners effectively deploy - and/or when exaggerated notions of planners' influence have been cultivated $^{2}$. Real influence depends on understanding how markets will respond and similarly how institutional processes can engender either (unnecessary) resistance or lines of support, depending on how they are attended to (Gordon, 2016). 
VI. Realistic planning for how implementation can be secured is a vital element of strategic planning, not an add-on. This is a matter of developing practice (and reflecting continuously on that, as Schon (1983) emphasised), as much as of sophisticated ideas. Working strategically to build co-operative relations, shared understandings, and credibility as a mobiliser of resources is intrinsic to pursuing a long-run approach, particularly where continuity of external patronage cannot be counted on.

\section{Learning from Past Experience}

The UK (particularly England) has a rather long history of engagements with strategic spatial planning, effectively starting with the internationally recognised example of Abercrombie's 1944 Greater London Plan, dating from war years with an unusual degree of economic planning and motivational drive toward designing a better future. This plan was archetypal in its neat logic, assuming effective economic restraint of aggregate growth across the region, designing a Green Belt to physically 'contain' the urban core, and providing for a system of planned population movement out to New Towns to relieve the overcrowding of housing in inner areas (Hall, 1988). In practice, restraint of a new service economy was ineffective, the achieved scale of New Towns was too small, and population decentralisation was achieved very largely through private initiatives ${ }^{3}$, commonly by leap-frogging a Green Belt, the width of which got greatly extended in response to local community demands (Hall et al., 1973). That element was the only one to be fully implemented, because it simply involved saying 'no' and did not depend on infrastructural support. Growth was not really constrained, though population was decentralised on a very large scale, essentially through market forces which the plan had not considered (Buck et al., 1986).

During the following 75 years, strategic planning activity has been intermittent, whether because it was seen as laying down blueprints which only occasionally required servicing, or new governments opposed it in principle (as during the Thatcher years, and again since 2010). Or sometimes, because it seemed an answer to a problem briefly topping the national political agenda - consistent with Wannop's (1995) view of British regional planning as a 'mercurial, often ephemeral' form of crisis management (p. xv).

An example of the last of these was the appearance in the late 1960s, during a (Labour) government favourable to planning of all kinds, of a quite sudden upturn in national population growth projections. This stimulated a unique Long Term Population Distribution planning exercise, making a case for development of a set of substantial new cities (DOE 1971). This was on grounds very largely independent of that population growth materialising - and a matter of conflict between rival physical and economic planning departments (O'Hara, 2007). But it was a deflation of the projections, and election of a new (Conservative) government, that led to abandonment of further strategic work.

At the sub-national scale within England, strategy/ strategic plan-producing regional planning bodies also came and went, in two separate waves (appointed planning councils and then indirectly elected assemblies, both set up by Labour governments) with ad hoc policy impacts only (see e.g. Breheny and Hall, 1984; Roberts and Lloyd, 1999; Baker and Wong, 2013). The one really sophisticated (and serious) experiment involved a Strategic Plan for the South East, with strong technical engagement from three levels of government 
(SEJPT, 1971). But even in this case a review after 6 years found there to have been no substantial impacts on infrastructure planning and resourcing (DSPSE, 1976, reported in Gordon, 2018).

At a city/sub-regional level, when elected London government was restored in 2000, after a 15 year hiatus, it was in the form of a directly elected Mayor leading an explicitly strategic (Greater London) authority, with preparation of a spatial strategy as a keystone in its responsibilities. This is a formal strategic plan, binding on boroughs, though itself required to be in conformity with a national planning policy framework. It is scarcely a regional plan, however, since (as the next section will make clear) it only covers the core of a much more extensive functional region. And the issue of how the London Plan should engage with communities and authorities in this region (now identified as the Wider South East) in meeting expected shortfalls in housing delivery, has been a key stimulus for new debate about means of renewing strategic regional planning (Bowie, 2018; CFN, 2017).

Responses from (Conservative) ministers have so far displayed an inconsistency that reflects shifting political pressures. Ministers' reactions to proposals (from the Inspector at one London Plan public examination) for some real engagement between London and authorities in neighbouring regions, have shifted from outright negativity in 2015 (Brandon Lewis writing to the Mayor of London) to evident impatience in 2019 that strategic cooperation was not advancing fast enough (MCHLG evidence to the next such examination ${ }^{4}$ ) - alongside growing national concern about housing supply shortfalls. And having swept away regional strategies in 2010 as part of a programme to 'end the hoarding of power within central government and top-down control of communities', the government's 2019 version of the National Planning Policy Framework involves vigorous enforcement of topdown local housing targets, directly from the centre.

Even from a very broad-brush review, this 75 year record of intermittent strategic regional planning practice in a country pioneering this activity, presents a very depressing picture. Some things are fundamentally wrong with the context, aspirations or the model from which we have been working. We have cases of:

- a classic (and classically statist) plan, with a clear vision but a shaky and rather blinkered analytic base, showing remarkable durability in the bluntest of its instruments, decades after their perverse effects were shown;

- a more sophisticated, better researched strategic plan which evidentlyy failed in getting key public infrastructural resources redirected to implement it; and

- many more initiatives, institutions and bits of strategic policy that came and went with the minor eddies and shifting currents of an unstable national politics.

Doubtless each of these three types of failure owes something to particular features of the UK/English setting - and maybe economic regimes of the times, though chiefly in the dependence of the Abercrombie Plan on a wartime version of Fordism. What all three seem to illustrate in different ways, however, is the unlikelihood (in any context) of effective strategic planning being achieved on the basis of a 'strategic plan' produced in (professional) isolation from intellectual and practical engagement with the more powerful economic and political forces in play. 


\section{Four Foundations for Realistically Sustainable Strategic Practice}

Putting together the principles set out above in section 2.2 with section 2.3 's reflections on the frustrating limits on effective practice in one illustrative national context, we identify four basic foundations for a de-centred model of strategic planning better suited to realising its defining functions. These involve:

1. an emphasis on building collective understandings and habits of co-operation across agencies/areas (in a pluralistic way, not just across 'a region');

2. reducing incentives to non-co-operation and boosting those for co-operation;

3. acquiring some enabling leadership from sources with a capacity to commit resources on a relevant scale and a durable basis;

4. establishing the grounds for negotiating acceptable deals among parties, notably by building trust in sources of evidence on likely impacts and uncertainties.

These foundations imply supportive action from central government and continuing commitment to enhance the quality of regional governance in a broader national interest. But their goal is to reduce reliance on specific initiatives, enthusiasms and agencies established by central government and avoid the associated risks of disruption each time there is a shift in political control or professional personnel. For instance, government might valuably provide leadership, such as in the form of a territorial minister for a collection of regions who is able to provide authoritative and coherent responses to resource bids and re-tune incentive schemes - but not act as top-down patron for strategic planning activity. Similarly, in respect of professional engagement, it should go without saying that this kind of de-centred planning model would need to be backed up by a lot of tactical and operational planning, that would include formal statutory plans - but without having an iconic Strategic Regional Plan as its focus.

\section{An Illustrative Case: Steering Population Dynamics in a Mega-City Region}

\section{Why Migration Flows are Crucial for Strategic Planning of (Super) Metro Regions}

To illustrate in more concrete terms the problems and potential of different forms of strategic planning, we take the case of the extended functional region centred on London. This typifies the situation of a mature metropolitan region, with a single dominant core and a momentum of spatial extension that is mediated by the interaction of dozens of overlapping spatial sub-markets for labour and housing, generating patterns of residential segregation at scales broad enough to strongly differentiate the politics of local government units across the region. In particular, we focus on issues involving population movement, which though obviously important in relation to infrastructure and service provision, and as influences on perceived quality of life in different communities, are not readily or clearly understood in this complex kind of setting.

One of the sources of obscurity about these facts is the sheer size of this extended region, though the spatial extent of the relevant territory is itself both unclear and contested. What is clear is that it has grown greatly in scale in the decades since the Abercrombie Plan, through the interplay between three broad currents of migration. Two of these have involved net flows into this part of the country - from overseas and from the less 
economically dynamic British 'north'. The third has been a strong deconcentrating trend with net migration out of the denser and more central parts of this territory, driven by a combination of increasing demands for more residential space and inelastic supply within these areas.

The strength of each of these currents has varied over time, with distinct periods of high/low net migration from the two external origins, and with fluctuations in the deconcentrating stream reflecting both macroeconomic factors and the scale of displacement effects from the two longer distance inflows. Chains of displacement also occur within the deconcentrating current itself, because housing supply is inelastic in many of its destination areas (especially in the metropolitan ring immediately around London) as well as in the regional core. These chains convert the short distance moves which households make for housing or environmental reasons into currents shifting population over distances of $100 \mathrm{kms}$ plus, well beyond the metropolitan ring (Gordon et al., 2017). These broad patterns and their dynamics are not only matters of strategic importance, but also have implications for how far issues arising from them can be effectively addressed, including of key importance: finding the right territorial focus for strategic analysis and governance; and appropriately relating forecasts, targets and scenarios in long term planning.

\section{Finding the right territorial focus for strategic planning}

From a classic strategic plan-making perspective, a fundamental issue is how to define the region to be covered. Rationally this could be seen in terms of trying to maximise the proportion of relevant causal interactions contained within the planning region. But inclusion in these terms has to be traded off against something else lest all strategic plans become national in scope. One such basis might be the degree of shared economic interest within the territory, though compromises over boundaries would still have to be made where two urbanised regions ran into each other - as in Warwickshire where the London and Birmingham migration regions join up. However, setting the problem up in this way runs into direct conflict with the notion that 'imagined territories' are of critical importance for a planning that depends on some degree of local popular consent for legitimacy and the build-up of support for desirable collective action. For long-run planning, there is also the issue that future development is liable to extend the effective bounds of the region in ways that cannot be wholly controlled.

In London's case, the likelihood of such change is highlighted by the truly enormous (some 40-fold) increase in the extent of its functional area over the past century (from that of the current Inner London to the London Metropolitan Region). This is due in part to its economic dynamism and a much extended public transport network. But it is also the result of motorisation, the 'sprawl' which this induced, and the unintended consequences of strategic planning, via a Green Belt intended to check that process. Its failure to effectively achieve that led perversely to a much wider diffusion of population beyond the Green Belt (Hall et al., 1973; Champion, 2002) and the extended chains of outward population movement mentioned above.

The direct effect of movement out into the commuter belt around London was to create a metropolitan region (with an Outer Metropolitan Area, or OMA), which was the focus of 
Hall's first (1963) work on London futures and remains close to researchers' definitions of its functional urban region (FUR), based essentially on commuter flows. With growing population displacement beyond the OMA, and the emergence of secondary employment concentrations both in the OMA and further out, a much more complex economic region has developed in the past 40 years or so, involving multiple inter-linked FURs. As the Greater South East (GSE), this became the focus of Hall's second (1989) work on London futures and formed the prototype of a new concept of polycentric metropoles or mega-city-regions (Hall and Pain, 2006). This is the scale at which informal moves toward some collaboration in planning have been discussed in the past 5 years, and more formal ones proposed (Bowie., 2018).

But recent research indicates that even this WSE combination of three former administrative regions doesn't represent the full scope of the migrational system of this agglomeration. The current reality is that the deconcentration current originating in London flows right through the OMA (much of it Green Belt) - with very little net effect on its population size, contrary to general belief - into both the outer ring of the WSE and a substantial Fringe area beyond this on the western and northern sides (Gordon et al., 2017). Including this Fringe in the territory appropriately covered by strategic planning of the quadrant implies a Still Wider South East (or SWSE) with a population of over 30 million (see Figure 1).

Figure 1

Zonal Ring Structure of the Still Wider South East

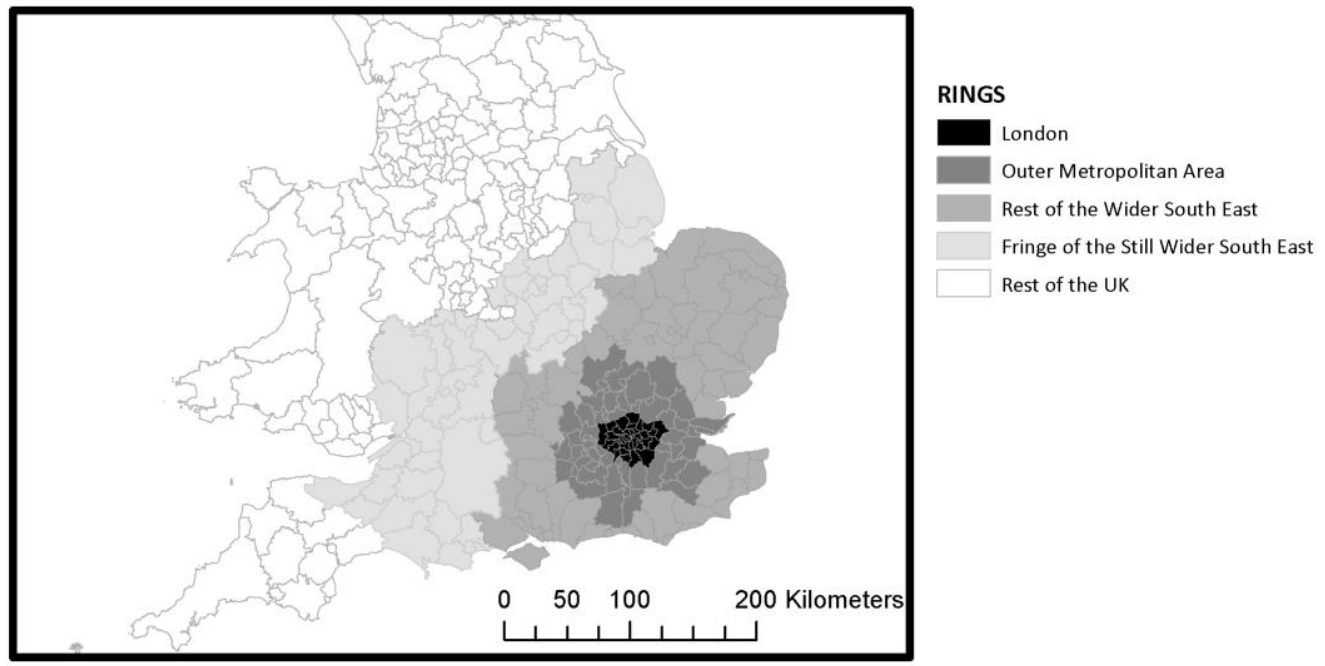

In contrast to this, the territory of 'London' government has been extended only once during this era, with the creation of Greater London in 1965 incorporating most of the city's pre-1939 extension. Though sometimes included in a South East administrative region that never had effective planning responsibilities - despite the one-off Strategic Plan for the 
South East referred to earlier. And since the early 1990s London has been formally separated from even its immediate hinterland. This has both reflected and reinforced territorially distinct 'imagined communities' and left governance of their inter-relations in the joint hands of national government and the market. The border between them is actually crossed by 200,000 or so migrants each year, but neither the dynamics of this interconnection nor how planning policies affect it are understood (or examined). And, unsurprisingly, weak efforts by central government in the early 2000s to mobilise a wider regional consciousness, in the national economic interest, made little impact (Cochrane, 2012), particularly at a time when national planning 'guidance' was reinforcing the defence of greenfield sites across the region. Since the re-establishment in 2000 of a London authority, in the form of an elected Mayoralty, with strategic responsibilities but dependence on the goodwill of central government for infrastructure funding, the consistent theme of London Plans developed by successive mayors (Ken Livingstone, Boris Johnson and Sadiq Khan, whose New London Plan is currently awaiting government approval) has been acceptance of responsibility for accommodating all of the population growth associated with the city's continuing economic growth. As was noted at the outset (Hall and Gordon, 2002) this entailed an 'almost impossible' acceleration of housebuilding dependent on a response from private developers that has proved consistently well below Plan targets. Actual population growth has been achieved largely through denser occupation of the existing stock by new migrants from poorer countries (Gordon, 2014). Despite arguments for alternative options (OLC, 2016b) the political imperative remains for London to 'consume its own smoke' in housing terms.

The imagined geographies (whether of politicians or citizens) are clearly at odds with the functional integration of the WSE. But, if strategic planning is to involve more than very occasional one-off exercises and if this requires active sub-national participation in relation to imaginable spaces, it is clear that simply translating it to an SWSE level is no sort of an answer. Hardly anyone actually imagines themselves as bound up with this space. And rising populist feeling (signalled here as elsewhere by the Brexit referendum) won't encourage that. Nor is there any chance that national government is going to devolve strategic responsibilities for an area containing a majority of England's population. Other ways have to be found to broaden both understanding and action beyond localities and 'fortress London' - and beyond superficial short-termism.

One useful positive step which has been proposed is reinstatement of technical support arrangements at a pan-WSE level, building on the model of the former SERPLAN 'standing conference' (Swain, 2018). But it needs a remit extended much further into the development and dissemination of a common understanding of processes (not least those affecting population dynamics, as the report drawn on in this section was intended to do) across the various parts of the WSE and its external borders (OLC, 2016a, Swain, 2018). Application of this kind of intelligence at a strategic level and on the continuing basis that is required would have to rest on development of the kind of collaborative negotiated bases for advancing shareable interests discussed in the previous section, and emphasised in the OLC (2016a) agenda for the WSE.

Beyond this, however, it is important to understand the political dimension of selective outward migration within the region, which encourages defensive solidarities between 
political communities with shared suspicions about the interests of others. Thus when (from 1998 to 2010) a South East region -comprised of those parts of the WSE, to the south east, south west, west and north west of London - had an elected regional chamber, the one shared basis of communal identity involved resistance to incursions by more migrants from London. This tended to obscure both the very different positions within the regional migration system of places within the OMA versus those further out and the fact that an integrated housing market across the whole SWSE gave residents of all areas a similar stake in resolving housing supply constraints. From this perspective, if political integration of the extended region is unfeasible, collaborative arrangements cutting across the rings, are a much more promising route toward the development of positive-sum spatial strategies (Mace and Gordon, 2016).

One spatial framework for these is set of radial growth/coordination corridors identified in the Key Diagram of successive London Plans, though with very limited practical development. A partial exception is the London-Stansted-Cambridge Corridor Consortium, a bottom-up initiative building on an idea from the Blair government's 2003 Sustainable Communities Plan. These corridors have been seen primarily as means of securing economic and social gains by promoting linkages between related activities with different locational requirements. But, because of their roles as migration and commuting corridors, cutting across the rings (with their different situations and populations) they could also offer the prospect of developing imagined geographies more conducive to collective strategic action, and credible deals made by partners with trustworthy records.

\section{Thinking strategically about population dynamics: projections, forecasts and scenarios}

With its focus on the longer term patterns of development, over broader territories and the scope for qualitatively different approaches the kind of information or guidance that strategic planning requires about likely and possible future developments is rather different from that required for statutorily-based operational planning - even in basic and familiar fields such as that of population change.

In the UK at least, practice with respect to demographic forecasting in the more routine contexts is heavily shaped by some combination of nationally mandated projections and accepted statistical methodologies. These are substantially trend-based, except where there is some very strong policy guidance as to what should happen (e.g. to international migration). This is not only to make best use of available data but to secure some evident objectivity and independence from either speculative ideas or the vested interests of particular groups in different interpretations of trends or possible changes in these. One important example in the case of those areas which are 'open' in housing/labour market terms involves use of projections of future population or household numbers in deriving the scale of housing needs which authorities should plan for - notably in those regions where there is resistance to additional development.

When trend-based population projections are used as a key input into defining future need and setting building targets, there is an obvious element of circularity in the procedure, since areas which have built more houses in the past will find themselves with higher population projections and larger targets for future construction, while others which have failed in (or resisted) development in recent years are likely to face less challenging targets 
in future. That is not, in itself a legitimate technical ground for challenging projections, whereas the choice of base period to extrapolate migration trends or household formation rates can be an important one (Champion, 2019).

What is lost in this essentially technical process of sharing out responsibility for future growth (and/or entitlement to additional infrastructure/services) is any concern with causality in terms of such key considerations as the reasons why a trend may be expected to 'bend', the policy/implementation options (locally or elsewhere) that would be expected to make a real difference, and the identifiable sources of major uncertainties that deserve particular monitoring, contingency plans or choice of more resilient strategies. Examples of all of these concerns may be found from analysis of the major migration currents into and within the WSE (Gordon et al., 2017).

An obvious example, though one that is consistently underplayed, is the growth in the importance of international migration to the region and especially to its core areas within the last 30 years, such that it has become a key push factor in the deconcentration current supplanting the previous main driver which had been the upward trend in real earnings (according to time series regression analyses by Gordon et al 2016; Gordon and Champion, forthcoming).

For a genuinely strategic planning in the region, preparing for alternative futures and not merely setting targets based on projected levels of need or capacity growth, an understanding of the main sources of uncertainty about population trends, particularly the strength of this deconcentration current, should be really important. This applies both to underlying uncertainties about the future course of known influences (in this case those of real personal income growth and of international migration), and to those which are more conjectural - including possible differences in mid-life movement patterns of the millennial generation of urban migrants as compared with their baby-boom predecessors; and whether longer residence will push up the space expectations of recent immigrants (Gordon et al, 2017)

There also needs to be a much wider understanding of the (more certain) relation between 'compact city' type policies of restricting development in rings close to London and the continuing spatial extension of the region into its very much less 'compact' fringes. But both of these also require a longer-term vision of the governance function which is decentred from shorter-term, operational concerns about trend projections and the making of an authoritative strategic plan.

\section{Learning from this case}

Population mobility and its ramifications are clearly just one dimension of strategic regional planning in the WSE, and one which arguably receives too much attention and generates too many worries with top-down allocative forms of regional plan. But it offers a relatively simple porthole into grasping the complexities with which any worthwhile strategic planning has to deal - and with the blindness there can be to key facets of these within actual existent forms of planning and regional politics. Mega-city regions present these in especially striking ways, and this particular region - with its distinctive functional and planning history - does so in its own way. But we would contend that it offers generic 
lessons (also relevant to places that are smaller, newer, more industrial and/or poorer) about the need to approach the challenges of strategic regional planning in a less classically monocentric fashion.

At one level, the lessons are ones of inadequate and unduly crude understandings - among practitioners, the policy community and to some extent among researchers too - of how the migration system and spatial housing markets actually function in this kind of region. In particular this involves:

1. the pervasive role of (largely voluntary) displacement processes in the face of inelastic local housing supplies (in which planning plays a role) in channelling currents of (mostly short-distance) population movement over very long distances,

2. the strong interlinkage of sub-regional housing markets, and

3. the autonomy of housing developers in relation to the phasing of new build.

But the fact that debate over population planning has excessively focused on the immediate overspill from London into areas in the OMA; targets for additions to the London housing stock are set quite unrealistically in relation to observable patterns of delivery; plans are assumed to shape where people move to, and residents in many areas assume they can cater simply for local needs; all also reflect political, administrative and professional considerations that are open to understanding and reshaping. Just not by adding another 'strategic' level to the status quo.

\section{Conclusion: Building a More a Durable Form of Strategic Regional Planning}

The ambition to plan strategically - with long/ wide horizons and attention to fundamental processes - is an old one, but with much greater salience in a world of increasingly complex, extended urban regions. Delivering on this ambition presents a series of challenges, of which probably the most fundamental is to accept that it is not simply a matter of enlarging the scope of established spatial planning processes and procedures. At the level of principle it needs to involve some of the kinds of decentring that we have discussed, away from the model of a single organisation producing an overarching Plan as the guiding framework for action and investment. Attitudinally, however, it also needs recognition of the various kinds and sources of failure in past strategic planning initiatives, and of the need to learn from these about how to achieve more, better and durable impacts in the short, medium and long run - with minimal waste of effort and frustration of expectations.

\section{The difference which a strategic perspective should make}

The potential of strategic regional planning depends very largely on it being clearly distinguished from mainstream day-to-day professional planning. The latter has to offer substantial degrees of certainty - about property rights, budgeting, demand for services, timetabling of infrastructure projects and so on - within the limits of force majeure, external shocks and internal failures that may cause some of these certainties to shift. Consistency, standard procedures to maximise coherence, and attention to formal regulations/policy frameworks all have value in this situation, as well as attention to relevant local influences and situations. 
Adding a strategic perspective should involve questioning all of these, in relation to a broader, longer-term view underpinned by a knowledge base about key processes, influences and interactions. In the classic rational planning tradition, however, there is no real disjunction between these levels, with strategic planning being just a more elevated (ideal-typical) version of the same activity, with a cleaner fact/value distinction, more opportunity to undertake rigorous analyses and a playing-down of local/temporary situational factors. As such, it is clearly a top-down exercise focused on producing a plan, which even if light on physical design will have a blueprint aspect to it - not least because it involves the kind of data handling and marketing effort that cannot be repeated frequently, still less adapted as situations and knowledge evolve.

The alternative 'political economy perspective' pursued here simply amounts to insisting on recognition that planning and the systems which it seeks to control (or more realistically help steer) involve very strong political/economic forces that interact with each other. In our judgement, this is an essential pre-condition if strategic planning is to have more positive and durable impacts than we have recognised in our review of British experience. At one level, this means building an understanding of these processes - along with an appreciation of their likely reactions to policies, and of practicable responses to those - into the intellectual framework of strategic initiatives. But at another level it means accepting that these forces make the classic equation of strategic planning with producing a strategic plan both unworkable and actually undesirable, particularly in relation to the 'regional' context where they have seemed particularly appropriate.

One reason, we would argue, is that at this level - and particularly in relation to a (currently) functional rather than (historic) administrative territory - there will be much less established legitimacy for it as representing an imaginable community, with a commonality of interests and values, than is the case either more locally or at a national level. One important reason for this is the way in which residential mobility within functionally integrated regions naturally engenders socially and culturally distinct local political communities often with high degrees of self-consciousness. Without work to build collaboration, this can be problematic for executing change that makes strategic sense, but more grievously so for attempts to endow a pan-regional authority with the power to produce and impose a meaningful strategic plan.

If that can't be effectively achieved on an independent basis, the default option is that of a central government initiative, which may be little more than symbolic, except in those few regions where a critical issue of national significance is identified. The main problem that we see (in the UK at least) is a lack of durable national-level commitment to meaningful action of the kind that strategic planning supposes. This is even more likely to be a fatal problem for proposals (such as CFN, 2017) to effectively integrate intra-regional strategic planning into an inter-regional framework of activity redistribution.

Hence the argument here is for pursuing this strategic dimension on a radically less 'centred' basis: actively encouraging bottom-up ad hoc collaborative groupings across ad hoc spaces (Cochrane, 2019); supporting development of strong bases of shared understanding and mutual trust, plus some identifiable 'leaders'; and thus enabling 
negotiation of compatible ways for furthering varied interests on a basis of durable resource commitments.

\section{Recognising and learning from past failures}

One of the themes of this paper - exemplified from UK experience though surely not limited to this setting - is of a pattern of failure in past strategic spatial planning initiatives to deliver positively effective strategic outcomes, for reasons that may seem extrinsic to the activity itself, but which really need to be understood if strategic planning is to become a functional reality, in times when this increasingly matters. Three of the arguably 'extrinsic' factors that are recognised involve: failures of political will/consistency; inadequate channels of implementation; and deficiencies in the knowledge base from which planners worked. Our argument is that these are actually generic issues that need to be addressed, not only at the level of planning practice, but also at that of theory, since they involve intrinsic problems with the classically iconic plan/planner-focused model that require a radical rethinking and opening up of the process.

Any scan of the literature of the last 20 years (only slightly reflected in our citations) will show numerous contributions with ideas for, and/or examples of, 'radical' reimaginings of strategic planning. Typically their radicalism is a normative one, focused on redressing recognised deficiencies in how strategic planning has addressed agendas of responsive governance, social cohesion, environmental sustainability and (even) economic competitiveness. In these respects they are progressive, but distinctively planner-centric in Salet's (2018) terms, and reflective of the problematic 'new conventional wisdom' (NCW) of the late 1990s (Gordon and Buck, 2005). More basically, they lack attention to how a collective capacity to effectively address strategic possibilities and challenges is to be developed in a real, material world where both political power and market forces have to be engaged with.

This may be seen even in the thoughtful and respected benchmark review by Albrechts, Healey and Kunzmann (2003) of lessons from three recent exemplars of a revived interest in strategic planning within European societies, under the strong influence of that NCW. Their cases involve three quite different settings: one with a strongly institutionalised regional planning culture (Hannover); one in which land use planning had been relatively weak, regulatory and localised in focus (Flanders); and one in which such characteristics were subsidiary to concerns with peace-making in an historically divided society (Northern Ireland). The authors' conclusions embrace both an optimism that a broader revival of strategic planning is underway and identification of some key processes and governance structures that need to be worked on. But while the latter is grounded in the case histories, the optimism seems entirely exogenous - and somewhat qualified by Kunzmann's cited argument that the NCW-inspired exercises are 'little more than a cosmetic covering that hides the growing disparities evolving in Europe' (op. cit', p. 115).

The first two cases are presented in a very positive light, and related to (differently) advantageous circumstances: a strong tradition of city-regional collaboration and leadership commitment that enabled extended bargaining processes to be effectively and productively concluded, in the Hannover case; and consensus across multiple elites of the need for a more action-oriented form of regional planning to respond to pressures arising from its 
international neighbours (and draw in academic expertise to facilitate innovative approaches), in the Flanders case. In the third, Northern Irish case, where underpinnings were weaker, and the spatial development strategy of less concern than confidence building and housing allocation, achievements seem both weaker and of less general relevance. The general lessons drawn from the first two cases in particular are entirely credible, with particularly perceptive observations about the importance of building institutional alliances and identifying approaches that are flexible, future-oriented, and politically acceptable. What such reviews crucially lack, however, is attention to cases where effective strategic action has not been forthcoming, whether analyses of contemporary ones where nondecisional barriers could be identified as operating, or reflection on historic cases of thwarted, ineffective or misdirected strategic activity. Understanding these might be expected to enable a more radical rethinking of how territorial governance can be made more (positively) strategic than is likely from observation of apparently effective examples.

What we offer here reflects a first approximation to what might be learned from giving greater attention to the collective experience of failed or non-strategic initiatives. The title invokes two familiar, indeed hackneyed, concepts - but with a significant twist to each. By 'sustainable' we mean not 'simply' generating plans that could plausibly secure a long term balance or rebalancing in/between key economic, social and environmental forces. But rather developing a set of processes and institutions to secure the basis for such planning and associated action itself to be pursued strategically over the long run. To borrow and reanglicise the French label for sustainable, we are particularly concerned with how (positive) strategic planning can itself be made durable in ways that it has generally not been. And by 'negotiated' we don't mean the rationalised/consistent representation within a planning document of a set of compromises arrived at by interactions with more/less diverse interests, which may or (often) not survive through subsequent 'implementation' processes. Rather, we are suggesting that for an effectively strategic dimension to planning, processes of negotiation and committing (or to put it more bluntly 'deal-making') should be seen as at the centre of a continuing and developing practice. This practice would engage with and be expressed in a variety of operational, shorter-term, localised or more specialist plans, rather than according centrality to any singular 'strategic' plan of the conventional professional kind.

\section{Acknowledgments}

This paper has benefitted from discussions in the Regional Planning Futures sessions at the RSA 2018 Winter Conference in London; with the London and Wider South East Strategic Planning Network convened by Duncan Bowie and Corinne Swain; and with colleagues in LSE London and CURDS at Newcastle University. More specifically, we appreciate the critical comments on earlier drafts from an anonymous referee and the issue editors, which led to a substantial strengthening of the paper's argument. 


\section{References}

Albrechts, L. (2013) 'Reframing strategic spatial planning by using a co-production perspective, Planning Theory, 12, 46-63.

Albrechts, L., Balducci, A. and Hillier, J. (eds.) (2017) Situated Practices of Strategic Planning, London: Taylor and Francis Albrechts, L. Healey, P. and Kunzmann, K.R. (2003) 'Strategic planning and regional governance in Europe', Journal of the American Planning Association, 69 (2), 113-129.

Baker, M. and Wong, C. (2013) 'The Delusion of Strategic Spatial Planning: What's Left After the Labour Government's English Regional Experiment?', Planning Practice and Research, 28, 83-103.

Bowie, D. (ed.) (2018) 'Strategic planning for London and the Wider South East', special section, Town and Country Planning, 87 (10) 395-419.

Breheny, M. and Hall P, (1984) 'The strange death of strategic planning and the victory of the know-nothing school', Built Environment, 10, 95-99.

Buck, N., Gordon, I.R. and Young, K. (1986) 'Decentralisation in the metropolitan region', ch. 3 in The London Employment Problem, Oxford: Oxford University Press.

Champion, A.G. (2002) The Containment of Urban Britain: retrospect and prospect, Milan: FrancoAngeli.

Champion, T. (2019) 'How many extra people should London be planning for?' Geography, 104, 160-165.

Cheshire, P. and Gordon, I.R. (1996) 'Territorial competition and the predictability of collective (in)action', International Journal of Urban and Regional Research, 20, 383399.

Cochrane, A. (2012) 'Making up a region: the rise and fall of the "South East of England" as a political territory', Environment and Planning C: Government and Policy, 30, 95-108.

Cochrane, A. (2019) 'in and beyond local governance: making up new spaces of governance', Local Government Studies. DOI: 10.1080/03003930.2019.1644321

Common Futures Network (2017) Towards a Common Future: a new agenda for England and the UK, http://commonfuturesnetwork.org/mdocuments-library?mdocscat=mdocs-cat-28\&att=null

Davoudi, S. (2018) 'Imagination and spatial imaginaries', Town Planning Review, 89, 97-107.

Department of the Environment (1971) Long Term Population Distribution in Great Britain: report of an interdepartmental study group, London: HMSO.

Development of the Strategic Plan for the South East team (1976) 'Implementation', in Review of the Strategy for the South East: Report of the Resources Group, London: Department of the Environment.

Fainstein, S. and De Fillipis, J. (2015) 'The Structure and Debates of Planning Theory ', in Fainstein, S. and De Filippis, J. (eds.) Readings in Planning Theory, $4^{\text {th }}$ edition, Chichester: Wiley: Blackwell.

Faludi, A. (1973) Planning Theory, Oxford: Pergamon.

Friedmann, J. (1993) 'Toward a non-Euclidean mode of planning', Journal of the American Planning Association, 59, 482-485.

Friedmann, J. (2012) 'Planning theory revisited', ch. 7 in Insurgencies: essays in planning theory, London: Routledge. 
Gordon, I.R. (2006) 'Finding institutional leadership for regional networks: the case of London and the Greater South East, in W. Salet (ed.) Synergy in Urban Networks, The Hague: Sdu, 136-160.

Gordon, I.R. (2014) 'Fitting a quart in a pint pot?: Development, displacement and/or densification in the London region'. In: Kochan, Ben, (ed.) Migration and London's Growth. LSE London, London School of Economics and Political Science, London, pp. 41-55.

Gordon, I.R. (2016) 'Functional integration, political conflict and muddled metropolitanism in the London region: 1850-2016', in A Cole and R Payre (eds.): Cities as Political Objects, Cheltenham: Edward Elgar, pp.31-55.

Gordon, I.R. (2018) 'Getting (more) real in planning for London and the Wider South East, Town and Country Planning, 87 (10), 415-419.

Gordon, I.R. and Buck, N.H. (2005) 'Introduction: Cities in the New Conventional Wisdom', ch. 1 in N.H. Buck, I.R.Gordon, A. Harding (eds.) Changing Cities: rethinking urban competitiveness, cohesion and governance, Basingstoke, Palgrave Macmillan.

Gordon, I.R., Champion, A.G., McGregor, N. and Whitehead, C.M.E. (2017) Migration Influences and Implications for Population Dynamics in the Wider South, report to the East of England Local Government Association. London School of Economics. http://Iselondonhousing.org/wp-content/uploads/2018/01/EELGA-Mlgration-

Project Main-Report plusExec.pdf

Gordon, I.R. and Champion, A.G. (forthcoming) The dynamics of migration flows and population shifts in England's metropolitan super-region.

Hall, P.G. (1963) London 2000, London: Faber.

Hall, P.G. (1989) London 2001, London: Unwin Hyman.

Hall, P.G. (1988) 'the city in the region: the birth of regional planning: Edinburgh, New York and London 1900-40, ch. 5 of Cities of Tomorrow: an intellectual history of planning and design in the twentieth century, Oxford: Blackwell.

Hall, P.G, Gracey, H., Drewett, R. and Thomas, R. (1973) The Containment of Urban England, London: Allen and Unwin.

Hall, P.G. and Gordon, I.R. (2002) 'Postscript: the Mayor's London Plan', in Buck, N., Gordon, I.R., Hall, P.G., Harloe, M. and Kleinman, M. (2002) Working Capital: life and labour in contemporary London, London: Routledge, pp. 388-392.

Hall, P.G. and Pain, K. (2006) The Polycentric Metropolis: learning from Mega-City Regions in Europe, London: Earthscan.

Healey, P. (1992) 'Planning through debate: the communicative turn in planning theory', Town Planning Review, Lindblom, C.E. (1965) The Intelligence of Democracy: decision-making through mutual adjustment, New York: Free Press.

London Stansted Cambridge Corridor Growth Commission (2016) Findings and Recommendations: The Next Global Knowledge Region: setting the ambitions and delivering the vision. http://www.Isccgrowthcommission.org.uk/?p=812

Mace, A. and Gordon, I.R. (2016) A $21^{\text {st }}$ Century Metropolitan Green Belt, London: London School, of Economics. http://eprints.Ise.ac.uk/68012/

Mace, A. (2019) 'How real is networked planning? When a corridor region meets green belt', paper presented in the 'Planning Regional Futures' session of the RSA London conference on New Horizons for Cities and Regions in a Changing World . 
Mayor of London (2019) London Plan: spatial development strategy for London, Intend to Publish version, London: Greater London Authority, December. https://www.london.gov.uk/sites/default/files/intend to publish - clean.pdf

Nelles, J. (2012) Comparative Metropolitan Policy: governing beyond regional boundaries in the imagined metropolis, Abingdon: Routledge.

O'Hara, G. (2007) From Dreams to Disillusionment: economic and social planning in 1960s Britain, Basingstoke: Palgrave Macmillan.

Outer London Commission (2016a) Coordinating Strategic Policy and Infrastructure Investment across the Wider South East, 5th report to the Mayor of London, London: Greater London Authority.

Outer London Commission (2016b) Accommodating London's Growth, $7^{\text {th }}$ report to the Mayor of London, London: Greater London Authority.

Rein, M. (1969) 'Social planning: the search for legitimacy', Journal of the American Institute of Planners, 35, 233-244.

Roberts, P. and Lloyd, G. (1999) 'Institutional aspects of regional planning, management, and development: models and lessons from the English experience' Environment and Planning B: Planning and Design, 26, 517531

Salet, W. (2017) 'Revisiting strategic spatial planning: a critical act of reconstruction', ch. 23 in Albrechts, et al (op. cit.),

Schon, D.A. (1983) The reflective practitioner: how professionals think in action. Aldershot: Ashgate.

South East Joint Planning Team (1971) Strategic Plan for the South East, London: HMSO.

Swain, C. (2018) 'Towards a London city-regional intelligence base -the art of the possible', Town and Country Planning, 87 398-401.

Wannop, U. (1995) The Regional Imperative, London: Jessica Kingsley.

$\mathrm{Xu}$, J. and Yeh, A.G.O (2017) 'Regional strategic planning for China's Pearl River Delta', in Albrechts et al. (op.cit), 25-44.

\section{Notes}

\footnotetext{
${ }^{1}$ This is an adapted version of Rein's (1969) original taxonomy of available sources of legitimation for planning practice. In our version the role of a socially licensed professional, represents a tamer, more institutionalised but politically defensible, counterpart to his 'guerrilla' role which has planners striving to enhance governmental competence and responsiveness by any means available. If not specifically one for 'planners' his guerrilla role does, however, have something in common with the view of strategic planning (as practice) for which we are arguing..

2 either on their own behalf to build credibility in the competition for influence, or by antagonists seeking a fall-guy for unwanted outcomes of other forces

3 Views about whether population and employment dispersal were a good thing vary. But its scale during the period when planners actively favoured it was (and is) commonly supposed to be a result of planning. In fact, however, even in a peak period planned movement accounted only $15 \%$ of net moves out of London (DOE, 1971), and a similarly modest proportion of London job losses (Buck et al., 1986, p. 59).
}

${ }^{4}$ MCHLG written representation on Matter 16 of the London Plan's Examination in Public. https://www.london.gov.uk/sites/default/files/m16 mhclg 2631.pdf

${ }^{5}$ with a credible power to commit to a line of action. 